\title{
Mastite Puerperal: Estudo de Fatores Predisponentes
}

\author{
Puerperal Mastitis: Study of Predisposing Factors
}

Acilegna do Nascimento Sales, Graciete Oliveira Vieira, Maria do Socorro de Queiroz Moura Suelly Pinto Teixeira de Morais Araújo Almeida, Tatiana de Oliveira Vieira

\begin{abstract}
RESUM0
Objetivos: conhecer as características clínicas e bacteriológicas da mastite, classificação e tratamento.

Métodos: as pacientes foram inquiridas sobre dados pessoais, pré-natal, atendimento no parto, no puerpério e quadro clínico. A mastite foi classificada pelos critérios de Vinha. Nos casos que evoluíram para abscesso, foi realizada análise bacteriológica, utilizando-se o meio de cultura caldo de enriquecimento Tryptone Soya Broth.

Resultados: das 70 lactantes, 57\% eram primiparas, 57\% com idade entre 20 e 29 anos e 51\% com $1^{\circ}$ grau incompleto. A renda era menor que um salário mínimo em $63 \%$ dos casos. Exerciam atividade domiciliar sem apoio em 66\% dos casos. Em 50\%, as mamas não foram examinadas. No pré-natal não tiveram orientação sobre aleitamento e ordenha em respectivamente $50 \%$ e $58 \%$ dos casos. Em 63\% o parto não foi em hospitais Amigos da Criança. Ocorreu ingurgitamento em 46\% e fissura mamilar em 47\% dos casos. Na classificação citada: $44 \%$ eram do tipo lobar, $39 \%$ ampolar e $17 \%$ glandular. No material de cultura houve crescimento de Staphylococcus aureus em $55 \%$.

Conclusões: fatores como baixa escolaridade, baixa renda, atividade familiar sem apoio, primiparidade e falta de orientação são fatores de risco para o aparecimento da mastite.
\end{abstract}

PALAVRAS-CHAVE: Aleitamento materno. Amamentação. Infecção puerperal.

\section{Introdução}

O leite humano é o alimento ideal para o recém-nascido e o lactente e nenhum outro alimento poderá substituí-lo com vantagem. A amamentação forma uma base biológica e emocional tanto para a saúde da mãe quanto da criança.

Apesar da excelência do leite humano, o desmame precoce é muito freqüente. No Brasil, a mediana de aleitamento predominante foi de 72 dias $^{1}$. A região nordeste apresentou a mais baixa mediana de aleitamento materno: 41 dias. Na cidade de Feira de Santana, no entanto, foi encontrada duração média do aleitamento de 9 meses $^{2}$. Várias medidas foram tomadas em nível nacional, com realização de programas de incenCentro de Referência para o Incentivo ao Aleitamento Materno e Banco de Leite Humano do Hospital Geral Clériston Andrade (HGCA) / $2^{a}$ DIRES/ Secretaria de Saúde do Estado da Bahia. Correspondência:

Graciete Oliveira Vieira

Rua Barão do Rio Branco, 1499

44025-000 - Feira de Santana - Bahia

Fone: (75) 625-4156 - Fax: 221-3884

e-mail: vieira@nway.com.br tivo ao aleitamento materno, e trabalhos têm demonstrado uma tendência ao aumento da prática de amamentar ${ }^{1}$. Um dos programas implantados foi a Iniciativa Hospital Amigo da Criança, no qual é realizado um trabalho de promoção e incentivo ao aleitamento materno no pré-natal, sala de parto, alojamento conjunto, berçário e ambulatório de puericultura. O Hospital Geral Clériston Andrade (HGCA), onde funciona o Centro de Referência para o Incentivo ao Aleitamento Materno (CIAMA) e Banco de Leite Humano $(\mathrm{BLH})$, recebeu o título de "Hospital Amigo da Criança” no ano de 1994. Por ser um serviço de referência, os profissionais de saúde de outros hospitais, postos de saúde e consultórios encaminham rotineiramente casos nos quais se diagnosticam complicações referentes à mama puerperal para avaliação e tratamento, e dentre estas a mastite puerperal.

A mastite puerperal ou da lactação é um processo infeccioso agudo das glândulas mamárias que acomete mulheres em fase de lactação, com achados clínicos que vão desde a inflamação focal, com sintomas sistêmicos como febre, 
mal-estar geral, astenia, calafrios e prostração, até abscessos e septicemia ${ }^{3-5}$. Devido ao desconforto e à dor, e também por acreditarem que o leite da mama afetada fará mal ao bebê, muitas mulheres desmamam precocemente os seus filhos, se não forem adequadamente orientadas e apoiadas ${ }^{6}$. Dados mostram que a mastite acomete, em média, 2 a $6 \%$ das mulheres que amamentam ${ }^{7}$. Estudos recentes prospectivos mostram incidência mais elevada de até $27 \%$, com $6,5 \%$ de recorrência ${ }^{8,9}$.

As mastites são causadas por diversos microrganismos, prevalecendo o Staphylococcus aureus como agente etiológico em 50 a $60 \%$ dos $\operatorname{casos}^{11}$. Dentre os fatores que predispõem a mastite prevalecem a fadiga, o estresse, fissuras nos mamilos, obstrução ductal e ingurgitamento mamário ${ }^{8,11,12}$.

A mastite, quando não tratada precocemente, pode evoluir para abscesso ${ }^{13}$. O melhor tratamento é a massagem, seguida de ordenha, aplicação de calor local e/ou frio, aumento de ingestão de líquidos e repouso ${ }^{11}$. A massagem facilita a fluidificação do leite por transferência de energia cinética, utilizada para rompimento das interações intermoleculares que se estabelecem no leite acumulado no interior da mama, além de estimular a síntese de ocitocina necessária ao reflexo de ejeção do leite ${ }^{14}$. Pode ser necessário o uso de analgésicos, antitérmicos e antibióticos ${ }^{15}$. Os antibióticos mais indicados são as penicilinas resistentes a penicilinase ou as cefalosporinas, que cobrem Staphylococcus aureus produtores de betalactamase, bactéria de maior prevalência nos processos de mastite. A dicloxacilina, antibiótico do grupo da penicilina, é também indicada.

Essas drogas são consideradas seguras durante a lactação, pois as quantidades excretadas no leite são mínimas devido a sua alta taxa de ligação com as proteínas plasmáticas maternas ${ }^{11}$. A manutenção da amamentação está indicada, porque o leite materno é rico em anticorpos e fatores antibacterianos ${ }^{4,14}$, e as toxinas das bactérias quando ingeridas são destruídas no tubo digestivo $^{16}$. Por outro lado, o desmame abrupto favorece o aumento da estase láctea com possível formação de abscesso e também pode gerar traumas psicofisiológicos para mãe e bebê $\hat{e}^{8,17}$.

Estes problemas poderiam ser prevenidos se as mulheres fossem orientadas quanto às técnicas adequadas de amamentação e ordenha. É importante também o acompanhamento das mães que amamentam para que haja a detecção de problemas como a fissura mamilar e ingurgitamento mamário, possibilitando a intervenção precoce ${ }^{6,18}$.

Como o objetivo primordial desse serviço é o incentivo ao aleitamento materno, questionouse quais as características clínicas e bacteriológicas mais freqüentemente observadas nas mulheres com mastite puerperal, atendidas no CIAMA/BLH do HGCA, fornecendo assim subsídios aos profissionais de saúde, para prevenção, detecção e intervenção precoce.

\section{Pacientes e Métodos}

Realizamos um estudo descritivo no CIAMA/BLH no período de dezembro de 1996 a janeiro de 1998, sendo atendidas e acompanhadas setenta mulheres com diagnóstico de mastite. As pacientes procuraram atendimento espontaneamente ou encaminhadas por outros serviços e profissionais da área de saúde, com o quadro de mastite já instalado e na grande maioria com formação de abscesso.

Todas as pacientes foram entrevistadas, utilizando-se formulários padronizados com perguntas sobre o atendimento durante o pré-natal, na sala de parto e alojamento conjunto.

A mastite foi classificada segundo os critérios de Vinha ${ }^{13}$ : em: lobar, quando havia comprometimento de uma região; ampolar, quando havia processo inflamatório de parte ou de toda a aréola; glandular, quando havia envolvimento de toda a glândula mamária (Figura 1) e abscesso mamário quando no local infeccionado havia ponto de flutuação. O tipo de aleitamento foi classificado como exclusivo, quando não havia introdução de nenhum outro líquido; predominante, quando o leite materno era a principal fonte, mas se usava chá, água ou suco, mas nenhum outro leite ou alimento semi-sólido; ou complementar, quando havia complemento alimentar semi-sólido ou sólido.

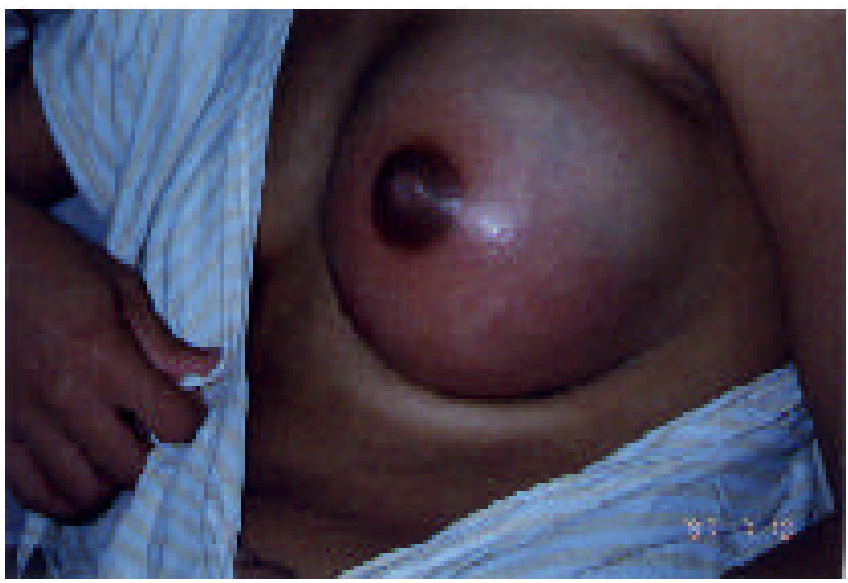

Figura 1 - Mastite puerperal, do tipo glandular, com envolvimento de toda a glândula mamária, segundo a classificação de Vinha ${ }^{13}$. 
Foi realizado exame das mamas de todas as pacientes, acompanhadas durante a evolução do processo da mastite, que retornavam ao serviço diariamente ou de dois em dois dias a depender da gravidade do caso, até a alta. No caso de mulheres que não compareciam quando aprazadas, eram feitas visitas domiciliares para controle.

Foi utilizado para o tratamento das mastites o antibiótico cefalexina num período de 7 a 14 dias, fornecido gratuitamente pelo Serviço. Para as pacientes com hipertermia e/ou dor era indicado o uso de antitérmicos, dando-se preferência ao acetaminofeno. Utilizou-se técnica de massagem manual ou massagem com uso de massageador elétrico na mama afetada, uso de compressas mornas e/ou compressas geladas e ordenha manual e/ou elétrica para esvaziamento de alívio na mama afetada.

A técnica de ordenha e de massagem, se manual ou elétrica, depende da preferência da paciente, das condições de ingurgitamento mamário ou da obstrução de ductos. No atendimento da paciente no CIAMA/BLH são utilizadas compressas mornas nas situações de intumescimento mamário, para facilitar a ordenha, seguidas do uso de compressas frias. Contudo, são recomendadas para as lactantes no domicílio a utilização de compressas frias em intervalos regulares, estabelecidos de acordo com o quadro clínico, que em situações de maior gravidade podem ser de $2 / 2$ horas, mas o tempo não pode ser superior a 15 minutos, pois a partir deste tempo ocorre o efeito rebote com vasodilatação e aumento do fluxo sanguíneo para compensar a vasoconstricção provocada pela redução da temperatura local ${ }^{14}$. As pacientes que evoluíram com a formação de abscessos foram submetidas a drenagem por médicos residentes do Serviço.

Foram coletadas amostras da secreção drenada, com o uso de swab, e foi realizada análise bacteriológica associada a antibiograma. A secreção colhida foi colocada em um caldo de enriquecimento Tryptone Soya Broth (TSB) ou Brain Heart Infusion (BHI) e no dia seguinte semeada em placa de ágar-sangue. As placas de ágar-sangue foram incubadas em estufas bacteriológicas a $37^{\circ} \mathrm{C}$ por um período de 24 a 48 horas. Das placas que apresentaram crescimento bacteriano foram feitas coloração para gram.

As bactérias gram positivas (Staphylococcus) foram identificadas por meio da coagulase (Staphylococcus aureus) e novobiocina (que diferencia Staphylococcus epidermidis do Staphylococcus saprofítico). As bactérias gram negativas foram identificadas mediante provas bioquímicas e oxidase, fazendo-se depois o antibiograma em ambos os casos.

Todas as mães foram estimuladas a manter a amamentação mesmo nos casos de abscesso.

Os resultados foram tratados manualmente pelos autores da pesquisa e os dados foram consolidados utilizando-se o software Epi Info versão 6.0.

O trabalho foi feito com conhecimento e autorização das pacientes e da Comissão de Ética e Pesquisa do hospital.

\section{Resultados}

Das 70 mulheres atendidas no CIAMA/ BLH/HGCA no período, $57 \%$ tinham de vinte a vinte e nove anos. Quanto ao grau de escolaridade, $51 \%$ tinham o primeiro grau incompleto. A renda familiar em salários mínimos em $63 \%$ foi menor ou igual a um e em $31 \%$ dos casos, entre dois e três. Com relação ao tipo de ocupação das mães, 66\% exerciam atividade domiciliar sem apoio.

Das $90 \%$ que fizeram o pré-natal, $44 \%$ haviam tido cinco ou mais consultas e $50 \%$ não tiveram as mamas examinadas. Metade das pacientes não recebeu orientação sobre aleitamento. Quanto à paridade, $57 \%$ eram primíparas e $26 \%$ secundíparas. Em 63\% dos casos, o parto ocorreu em hospitais sem o título "Hospital Amigo da Criança”.

A permanência em alojamento conjunto foi citada por $81 \%$ das pacientes. A primeira mamada ocorreu na sala de parto em $20 \%$ dos casos, $76 \%$ entre 2 e 24 horas e $4 \%$ dos recém-nascidos não mamaram. Quanto ao tipo de aleitamento, era exclusivo em 51\% dos casos, predominante em $16 \%$ e complementar em 24\%. Entre as mulheres que amamentavam, $74 \%$ o faziam em livre demanda. Quando inquiridas, 67\% não relatavam experiência anterior com amamentação. Das pacientes, $46 \%$ apresentaram as mamas ingurgitadas entre a $2^{\mathrm{a}}$ e a $4^{\mathrm{a}}$ semana $(\mathrm{Ta}-$ bela 1). Com relação à orientação sobre a ordenha, $58 \%$ não haviam sido orientadas e, das que foram orientadas, apenas $26 \%$ a sabiam fazer corretamente. A fissura mamilar estava presente em $47 \%$ das mulheres (Tabela 1). Em 79\% das pacientes, a mastite ocorreu nas primeiras oito semanas após o parto, sendo apenas um caso na primeira semana.

Ao exame físico, $79 \%$ das pacientes apresentaram mamilos protrusos. Quanto à classificação da mastite, 44\% eram do tipo lobar, 39\% do tipo ampolar e $17 \%$ do tipo glandular (Figura 
1). Do total, duas pacientes apresentaram mastite em ambas as mamas e uma paciente em glândula supranumerária; $84 \%$ evoluíram para abscesso. Das 59 pacientes que evoluíram para abscesso, foram analisadas as secreções de 46, com a identificação do Staphylococcus aureus em 55\% (Tabela 2). Metade das pacientes continuou a amamentar em ambas as mamas.

Tabela 1 - Tipo de ocorrência de ingurgitamento mamário e fissura mamilar após o parto.

\begin{tabular}{|c|c|c|c|c|}
\hline \multirow[b]{2}{*}{ Tempo } & \multicolumn{2}{|c|}{ Ingurgitamento mamário } & \multicolumn{2}{|c|}{ Fissura mamila } \\
\hline & $\mathrm{n}$ & $\%$ & $\mathbf{n}$ & $\%$ \\
\hline $1^{\mathrm{a}}$ semana & 14 & 20 & 12 & 17 \\
\hline $2^{\mathrm{a}}$ à $4^{\mathrm{a}}$ semana & 32 & 46 & 16 & 23 \\
\hline Após a $4^{\mathrm{a}}$ semana & 16 & 23 & 5 & 7 \\
\hline Não & 8 & 11 & 37 & 53 \\
\hline Total & 70 & 100 & 70 & 100 \\
\hline
\end{tabular}

Tabela 2 - Distribuição dos achados da cultura obtida da secreção de abscessos de 46 das 59 pacientes que evoluíram para abscesso.

\begin{tabular}{lrr}
\hline Tipo de bactéria & $\mathbf{n}$ & $\%$ \\
\hline Staphylococcus aureus & 25 & 55 \\
Staphylococcus epidermidis & 7 & 15 \\
Staphylococcus sp. & 3 & 7 \\
Enterobacter sp. & 1 & 2 \\
Klebsiella sp. & 1 & 2 \\
Escherichia coli & 2 & 4 \\
Ausência de crescimento* & 7 & 15 \\
Total & 46 & 100 \\
\hline
\end{tabular}

*Pacientes em uso de cefalexina

\section{Discussão}

Apesar da excelência do aleitamento materno e dos programas de incentivo e promoção realizados no pré-natal, sala de parto, alojamento conjunto e puerpério, existem dificuldades referentes ao manejo da lactação e à amamentação que podem culminar com o desmame precoce. Um destes problemas no puerpério é o aparecimento da mastite.

Das 70 pacientes estudadas, chama a atenção uma maior freqüência de casos de mastite nas mulheres com menor grau de escolaridade e baixa renda familiar, pois $51 \%$ dos casos tinham primeiro grau incompleto e a renda era em $63 \%$ menor ou igual a um salário mínimo. Outro fator observado foi que $66 \%$ das mães ti- nham atividade domiciliar sem apoio. Este achado reforça os dados encontrados na literatura que enfatizam a fadiga e o estresse como fatores predisponentes ao aparecimento da mastite ${ }^{8,12}$, pois diminuem as defesas maternas ${ }^{11}$. Este fato chama a atenção para a necessidade da ajuda e apoio emocional à puérpera por parte de outras mulheres, do marido e da família, na divisão das tarefas domésticas, para que a mãe disponha de mais tempo para a amamentação.

Em 79\% das pacientes a mastite ocorreu nas primeiras oito semanas após o parto. Resultados similares foram encontrados em outros estudos, como o de Kinlay et al. ${ }^{9}$, que em uma coorte prospectiva observou a ocorrência da maioria dos casos dentro das sete primeiras semanas após o parto $(75 \%)$. Desta maneira, torna-se de grande importância o acompanhamento das mães durante o período da lactação e, por isto, no momento da alta, devem ser encaminhadas para um serviço de apoio à amamentação.

A ocorrência de mastite tem sido relacionada também com o grau de paridade. Observamos que $57 \%$ das nossas pacientes eram primíparas, o que está de acordo com outros estudos que encontraram incidência semelhante, como o de Foxman et al. ${ }^{19}$, que encontrou índice de 59\%. Guando inquiridas com relação à experiência anterior com a amamentação, 67\% responderam que não tiveram. A falta de experiência pode levar à insegurança, gerando ansiedade, o que, por sua vez, pode interferir no processo da lactação e amamentação.

Em 63\% dos casos, o parto havia ocorrido em hospitais sem o título "Hospital Amigo da Criança”. Provavelmente programas adequados de incentivo ao aleitamento materno contribuem para diminuir problemas referentes à mama puerperal, contudo serão necessários novos estudos analíticos para confirmar esta hipótese.

Não se observou relação entre o tempo para o início da amamentação, seguido da permanência da mãe e filho em alojamento conjunto, e o aparecimento da mastite. Isto se explica pelo fato de a mastite se instalar após a alta hospitalar.

Há muito tem-se enfatizado a importância do incentivo ao aleitamento materno e manejo da lactação no pré-natal e alojamento conjunto, assim como a necessidade de que as mães sejam orientadas a esvaziar as mamas quando ingurgitadas ${ }^{10,11,20}$. Apesar do pré-natal ter sido realizado por $90 \%$ das pacientes, metade informava que suas mamas não haviam sido examinadas e metade não recebeu qualquer orientação sobre aleitamento materno. O mesmo aconteceu com relação à ordenha, já que $58 \%$ não tinham sido orientadas e, das $42 \%$ que o foram, 
apenas $26 \%$ sabiam proceder corretamente. A falta de orientação no período gestacional e puerperal, associada ao fato de as mães não saberem fazer a ordenha, pode ter contribuído para o aparecimento da mastite, já que um fator predisponente é o ingurgitamento mamário. No nosso estudo, $46 \%$ das pacientes apresentaram mamas ingurgitadas entre quinze e trinta dias após o parto, que foi também o período de maior aparecimento da mastite ${ }^{10,11}$.

A fissura de mamilo esteve presente em $47 \%$ das pacientes estudadas. A fissura pode ser a porta de entrada de bactérias pelos ductos lactíferos ou pelos linfáticos peri-ductais, interrompendo a primeira barreira de defesa ${ }^{11,21}$. As bactérias, encontrando condições apropriadas, disseminam-se nos diversos tecidos a partir de pequenas lesões de pele e mucosas ${ }^{22}$, principalmente o Staphylococcus aureus, que produz uma proteína de ligação à fibronectina, considerada um importante fator de virulência ${ }^{23}$.

Evoluíram para abscesso mamário $84 \%$ das pacientes. As mesmas procuraram atendimento tardio, com o quadro de mastite já instalado e em fase avançada. Segundo a literatura, quando o tratamento se inicia de forma tardia ou inadequada, há o aparecimento de abscesso em até $66 \%$ dos $\operatorname{casos}^{24}$. Daí a importância da instituição do tratamento precoce, entre 24 e 48 horas após o aparecimento dos primeiros sintomas ${ }^{10,11}$.

$\mathrm{Na}$ análise do material coletado, e realizado o estudo bacteriológico, observou-se uma predominância de Staphylococcus aureus, detectada em 55\% dos casos, o que está de acordo com trabalhos já realizados que confirmam a presença do Staphylococcus aureus numa taxa que varia entre 50 e $60 \%$, em situações semelhantes $^{10,11}$.

A mastite puerperal é um dos fatores relacionados ao desmame, e o conhecimento das suas características clínicas e bacteriológicas permite a realização de medidas de intervenção que, quando realizadas de maneira precoce, favorece a redução dos casos novos.

Estudos posteriores serão necessários para se determinar a incidência e os fatores de risco para a mastite em mulheres atendidas em hospitais que tenham ou não orientação no manejo da amamentação.

\section{SUMMARY}

Purpose: to investigate clinical and bacteriological aspects, follow-up and treatment of mastitis in our clinic.
Methods: this study was performed at Cleriston Andrade General Hospital. Patients were interviewed regarding personal data, prenatal care, care received during delivery and puerperium and clinical aspects. Their mastitides were classified by Vinha's criteria. The patients with abscesses had them drained for bacteriological study. Culture medium Tryptone Soya Broth was used.

Results: seventy nursing mothers were interviewed; $57 \%$ of them had given birth for the first time, $57 \%$ were between 20 and 29 years old, $51 \%$ had not finished elementary school, $63 \%$ had income less than the minimum wage, $66 \%$ of them had nobody to help with the housework. Out of the seventy females, $50 \%$ had not had their breasts examined. Approximately half of them had not been told how to breastfeed (50\%) or how to express breast milk (58\%). Sixty-three percent had not delivered in institutions designated by WHO as "Children's Friends Hospitals". Engorgement occurred in $46 \%$ of the cases and nipple fissures in 47\%. According to Vinha's criteria, 44\% had lobar, 39\% ampular and 17\% glandular locations. Presence of Staphylococcus aureus was detected in 55\% of the cases.

Conclusion: factors such as low schooling, low incomes, no assistance in housework, giving birth for the first time and lack of professional help contributed to occurrence of mastitis.

KEY WORDS: Breastfeeding. Puerperal infection.

\section{Agradecimentos}

À Dra. Liliane Mendes de Morais, pelas análises bacteriológicas. Aos residentes de ginecologia e obstetrícia e à equipe do Centro de Referência para o Incentivo ao Aleitamento Materno e Banco de Leite Humano, do Hospital Geral Clériston Andrade.

\section{Referências}

1. Ministério da Saúde. Manual de promoção do aleitamento materno: normas técnicas. $2^{\mathrm{a}}$ ed. Brasília; 1997. p.6.

2. Vieira GO, Glisser M, Araújo SPT, Sales AN. Indicadores do aleitamento materno na cidade de Feira de Santana, Bahia. J Pediatr (Rio de Janeiro) 1998; 74:11-6.

3. Linhares E. Distúrbios e patologia da lactação. Mastites. In: Rezende J, editor. Obstetrícia. $3^{a}$ ed. Rio de Janeiro: Guanabara Koogan; 1974. p.867-73.

4. Riordan J, Countryman BA. Basics of breastfeeding. Part II - The anatomy and psychophysiology of lactation. JOGN Nurs 1980; 9:210-3. 
5. Ziegel EE, Cranley MS. Enfermagem obstétrica. $8^{\mathrm{a}} \mathrm{ed}$. Rio de Janeiro: Guanabara; 1985. p.696.

6. Fetherston C. Management of lactation mastitis in a Western Australian cohort. Breastfeed Rev 1997; 5:13-9.

7. Kaufmann R, Foxman B. Mastitis among lactating women: occurrence and risk factors. Soc Sci Med $1991 ; 33: 701-5$.

8. Fetherston C. Characteristics of lactation mastitis in a Western Australian cohort. Breastfeed Rev 1997; 5:5-11.

9. Kinlay JR, O'Connell DL, Kinlay S. Incidence of mastitis in breastfeeding women during the six months after delivery: prospective cohort study. Med J Aust 1998; 169:310-2.

10.Livingstone V. Too much of a good thing. Maternal and infant hiperlactation syndromes. Can Fam Physician 1996; 42:89-99.

11.Lawrence RA. La lactancia materna. Una guia para la professión médica. $4^{\mathrm{a}}$ ed. Madrid: Mosby; 1996. p.267-73.

12.Riordan J, Auerbach KG. Breastfeeding and human lactation. Boston: Jones and Bartlett Publishers; 1993. p. 382-400.

13.Vinha VHP. Projeto aleitamento materno: autocuidado com a mama puerperal. $1^{\text {a }}$ ed. São Paulo: Sarvier; 1994. p.21-101.

14.Almeida JAG. Amamentação: um híbrido natureza - cultura. $1^{a}$ ed. Rio de Janeiro: FIOCRUZ; 1999. p.76-8.
15.Linhares E. Mamas. Lactação. In: Rezende J, editor. Obstetrícia. $3^{a}$ ed. Rio de Janeiro: Guanabara Koogan; 1974. p. 336-8.

16.Martins FJ. Como e porque amamentar. $2^{\mathrm{a}}$ ed. São Paulo: Sarvier; 1984. p.103-6.

17.Waletzky LR. Breastfeeding and weaning - some psychological considerations. Prim Care 1979; 6:341-55.

18.King, FS. Como ajudar as mães a amamentar. $1^{\mathrm{a}} \mathrm{ed}$. Brasília: Ministério da Saúde, Instituto Nacional de Alimentação e Nutrição; 1994. p. 44-58.

19.Foxman B, Schwartz ZK, Looman SJ. Breastfeeding practices and lactation mastitis. Soc Sci Med 1994; 38:755-61.

20.Jonsson S, Pulkkinen MO. Mastitis today: incidence, prevention and treatment. Ann Chir Gynaecol Suppl 1994; 208:84-7.

21.Arévalo Giron MC, Solórzano Santos F. Mastitis: contraindicacion de lactancia? Infectologia 1987; 7:383-5.

22.Gonçalves AJR, Rozembaum R, Cardoso FLL. Doenças estafilocócicas. Arq Bras Med 1987; 61:13-4.

23.Flock JI, Hienz SA, Heimdahl A, Schennings T. Reconsideration of the role of fibronectin binding in endocarditis caused by Staphylococcus aureus. Infect Immun 1996; 64:1876-8.

24.Johnson PE, Hanson KD. Acute puerperal mastitis in the augmented breast. Plast Reconstr Surg. 1996; 98:723-5.

\title{
RBGO
}

\section{é uma publicação da}

FEBRASGO

\section{e que aceita artigos provenientes de ginecologistas, obstetras e de outras especialidades.}

\author{
Portanto, publique!!! \\ Mande já seu artigo para RBGO
}

